\title{
Reflections on Waste Materials in the Creation of Craft Culture*
}

\author{
Quanheng Li \\ Guangdong Industry Polytechnic \\ Guangzhou, China
}

\begin{abstract}
Under the current trend of craft culture renaissance, under the situation that revival of traditional technology and the protection of intangible cultural heritage has become a hot topic today, under the emphasis on promoting the formation of green development methods and green life, the paper explores the recycling of waste materials in the creation of craft culture, hoping to help promote green development, form a spatial pattern, production mode and lifestyles that conserve resources and protect the environment as well as hoping to give an active play to the ecological culture construction and some useful thinking on the craft culture creators.
\end{abstract}

Keywords - waste materials; craft culture; green development; recycling

\section{INTRODUCTION}

"It is an inevitable requirement of implementing the new development concept that promoting the formation of green development modes and lifestyles. We must give high priority to ecological civilization construction in the overall work, adhere to the basic national policy of conserving resources and protecting the environment, and stick to the guidelines of saving priority, protection priority, and natural recovery in order to form a spatial pattern, production mode and lifestyles that conserve resources and protect the environment. Besides, efforts should be made to achieve synergy between economic and social development and ecological and environmental protection in order to create a good production and living environment for the people." It is the main content of forty-first collective learning of the CPC Central Committee Political Bureau on promoting the formation of a green development mode and lifestyle in the afternoon of May 26, 2017.

In terms of social development, the modernization of the craft culture is a spontaneous and conscious process, because the craft culture must have its own sense of time from ancient to modern time, from materials, craftsmanship, functions to formal languages and aesthetic methods, and its development is inseparable from social economy, culture, and the environment. Even in traditional craftsmanship, the products of the same category vary due to different times. Chinese craft culture pays attention to practices, forms, experience as well as its living heritage and handicraft

*Fund: Project for Training Excellent Young Teachers in Colleges and Universities in Guangdong Province (YQ2015173). characteristics. Craft culture is rich in variety and forms in its creations, and it has a variety of folk cultures: customs, traditional etiquette, religion and festivals.

The exploration of waste materials in craft cultural creation can not only respond to the overall layout of the "five-in-one" ecological civilization construction and promote the formation of green development methods, but also provide opportunities for the live transmission and development of craftsmanship.

\section{WASTE MATERIALS AND CRAFT CULTURE}

Reuse of waste materials is the process of dividing natural and man-made wastes and various types of waste into multiple layers of used materials, to work as products as much as possible directly or indirectly or to be used as products after being repaired, refurbished, and remanufactured continually, or reusing all kinds of or part of waste as part of other products and extending the service time and intensity of the product as many times or methods as possible to avoid the product become waste too early or too much. On the one hand, from the perspective of protecting the environment, it reduces resource consumption and achieves a sustainable development strategy. On the other hand, from a commercial perspective, it reduces costs and potential liability risks so as to increase competitiveness.

In the exploration of craft culture creation: waste materials, on the one hand, is the conservation and recycling of conventional and non-renewable resources, and it uses the arts of craft culture to reuse waste materials; on the other hand, shows the design principles of that renewable resources consumption should be as low as possible to create a spatial pattern, industrial structure, as well as production methods and lifestyle of saving resources and protecting the environment. It uses natural and man-made, and various wastes to give new sense of form and new life, and to convey the concepts of sustainable development and ecological design appropriately relying on the art. Besides, it has successfully built a visual form that adapts to the performance of the handicrafts with the visual effect of natural beauty, simple and elegant plot, and the emotions produced by culture symbols memory of the waste materials, so that the handicrafts can convey commodity information while being environmentally friendly. 


\section{FEASIBILITY OF WASTE MATERIALS IN CRAFT CULTURE CREATION}

First of all, on national policies: China has introduced many policies to give a lot of support for waste recycling, reuse, and resource recycling. China has promulgated the regulation and standardized industrial policies such as "Law of the People's Republic of China on energy conservation," "Law of the People's Republic of China on promoting circular economy," "Measures for the management of renewable resources recovery," and "China's Comprehensive Resource Utilization Technology Policy Outline". At the same time, in recent years, people have been more concerned with the concepts of green design and environmental protection, which play a great role of promotion on education. In addition, on forty-first collective learning of the CPC Central Committee Political Bureau, General Secretary Xi Jinping stressed once again that it is an inevitable requirement of implementing the new development concept that promoting the formation of green development modes and lifestyles. We must give high priority to ecological civilization construction in the overall work, adhere to the basic national policy of conserving resources and protecting the environment, and stick to the guidelines of saving priority, protection priority, and natural recovery in order to form a spatial pattern, production mode and lifestyles that conserve resources and protect the environment. Besides, efforts should be made to achieve synergy between economic and social development and ecological and environmental protection in order to create a good production and living environment for the people.

Second, on the consumption concept: masses of consumers have changed their consumption ideas, and began to pursue a green lifestyle. As sustainable development concept such as green design, eco-design, and waste recycling has attracted much attention, people have become more aware of eco-environment protection, and consumers have attached great importance to low-carbon and environmentally-friendly products. Especially for the young, they are more concerned about sustainable development concepts. In addition, in recent years, there have been the development tendencies such as international design trend of waste resources recycling, universalization of low-carbon life, and promotion on green development methods and lifestyles formation. Therefore, in the transformation of consumer's consumption concept, in the development environment of recycling of waste resources, and in the trend of promoting green development, there will be a place for the application of waste ceramic recycling in the design of daily necessities.

Third, in science and technology: In recent years, Chinese science and technology have also effectively helped waste resources to be recycled in a reasonable way, saved the development and production resources, optimized the industrial structure, and eliminated outdated and dangerous production capacity and technical skill, which determines the protection policy of environmental governance from the source. In addition, internationally existing technologies carry out mutual transfer and cooperation. At the Copenhagen conference, there was good news about the development of China's low-carbon economy. The Western countries are willing to make commitments for developing countries such as China to transfer low-carbon technologies through the ways of pushing forward "the Belt and Road" international cooperation summit forum, making solid progress in the "One Belt One Road" international production capacity cooperation, jointly developing thirdparty markets, technology transfer, joint venture cooperation and so on.

These factors all proved the feasibility of using waste materials in the creation of craft culture. Through exploring and researching, it can support the construction of ecological civilization, promote the formation of green development, and provide a living inheritance and development of handicraft culture.

\section{EXPLORATION AND THINKING ON WASTE MATERIALS IN CRAFT CULTURE CREATION}

\section{A. Memory Traces: Paying Attention to Cultural Symbols of Waste Materials}

The application of recycled waste materials in the creation of handicraft culture is a brand-new design concept and it give designers new ideas and new thinking points. Designers are also obliged to take the lead in promoting the green development modes and lifestyles, and guide consumers' consumption awareness of protecting the environment by using their creative achievement, so that the arts and crafts enter into the world of eco-environment protection earlier. Waste materials have been in our life for a long time, and we have known or contacted them before, but whether they can be reused to convey the consciousness of modern society, and whether the cultural memory and stories behind handicrafts can be seen are worth designers' thoughts. In recent years, with the increase of people's awareness of ecology and environmental protection, the design trend of waste recycling has been spreading. Designers have paid attention to the cultural symbols memory and inheritance of waste resources continuously. Waste materials have certain history and precipitation, and the stories and cultural memories behind them can evoke deeper understanding of consumers' ecological and environmental awareness. In the creation of handicrafts, the cultural symbols memory, inheritance and innovative design of waste materials can bring new and familiar feelings to consumers. It also has great significance for rich decoration and sense of form. It is not only a form of innovation, but the communication of information as well as a new approach of inheriting and developing the living craft culture.

\section{B. Material Properties: Focusing on the Presentation of Material Characteristics and Technological Characteristics}

In the creation of waste materials in handicraft culture, when using waste materials as design materials reflects lowcarbon design concepts, designers should pay more attention to the inherent characteristics of the waste materials. Besides, they should bring the characteristics of materials into full play to reflect the low-carbon and ecological design well, 
and guide consumers' awareness of environmental protection. The intrinsic characteristics of waste materials are determined by the composition, structure, and traces of the waste materials themselves. They are a kind of property that the materials naturally manifest when being used, and they are not limited by any external conditions. The inherent characteristics of waste materials include both physical and chemical properties.

At the same time, it is also necessary to pay attention to the display of waste materials processing technology. Technology and materials are complementary and are closely related to each other. There is no exception of craft culture creation. The material distinguishes itself from different species by its own unique properties, highlighting its own characteristics, and the craftsmanship can, in a certain sense, exhibit the material characteristics fully. Besides, it is necessary to pay attention to the sense quality of waste materials. The sense quality of waste materials are closely related to the structure, compositional factors, usage, environmental conditions and so on. Different waste materials exhibit different sense quality. For example, the old ship woods have an imperfect beauty, giving people the feeling of primitive simplicity; scrap metals give the impression of precipitation and indifference. In addition, the sense qualities of waste materials are also connected with the inherent properties of the materials, and also depend on the processing characteristics of the waste materials. Different waste materials and different processing methods and technologies give different expressions of sense quality. For waste materials, we should pay more attention to the characteristics of these materials, bring them into play to present the original material characteristics of the waste materials properly, and beautify the defects in a reasonable manner. Finally, the perfect effect of handicrafts will be presented to consumers.

\section{Inheritance and Innovation: the Combination of Contemporary Aesthetics and Traditional Crafts}

The progress of science and technology and the everchanging concepts have had a great influence on the art. Grasping the combination of contemporary aesthetics and traditional craft is one of the design ideas that cannot be ignored in handicrafts, and it is also an innovative way to develop handicrafts. In the art market where global cultural and artistic communications as well as diversified cultural and artistic forms are displayed in such a prosperous fashion, the combination of contemporary aesthetic consciousness and traditional craftsmanship, and the modernization of handicraft traditions can achieve the inheritance, development and prosperity of the handicrafts industry.

In the creation of craftsmanship culture, waste materials are combined with traditional craftsmanship through the contemporary aesthetics, which is in essence a creative change. The change in artistic concepts, the innovation of waste materials and application technology, and the combination of modernity and tradition, art and science have realized modernization of contemporary handicraft traditions. Modern handicrafts produced by traditional craftsmanship also meet the life demands of consumers and convey close interaction between people and people as well as people and society. Traditional craftsmanship has certain technical content and the features of adapting to nature, single inheritance mode, arbitrariness and empiricism of craftsmanship, etc. It is the carrier of national material and cultural symbols, and interprets the lifestyle, spiritual beliefs, value orientation and living conditions of an era. But the contemporary aesthetic reflects the aesthetic consciousness and aesthetic information of consumers in the current era. This kind of beauty is perceptual, and sensibility comes from the heart. Therefore, the "beauty" is the highest state of "human heart". This aesthetic consciousness is different in different times. Consumers of different ages will judge the aesthetic culture of handicrafts according to the aesthetic and cultural standards of different eras.

Handicrafts are the physical products meeting the real needs of consumers and the aesthetic consciousness of consumers in the current era as well as reflecting the aesthetic consciousness and real needs through material and cultural carriers. The embodiment of traditional craftsmanship is indispensable, and contemporary aesthetic consciousness is also an inherent need. Therefore, the creation of waste materials in the craft culture will be necessary to combine contemporary aesthetic consciousness with traditional craftsmanship, and it is also the key to the maturity of handicrafts.

\section{Green Cycle: Focusing on Promoting Green Development and Promoting Sustainable Design}

We should adhere to the basic national policy of conserving resources and protecting the environment, and stick to the guidelines of saving priority, protection priority, and natural recovery in order to form a spatial pattern, production mode and lifestyles that conserve resources and protect the environment. Besides, efforts should be made to achieve synergy between economic and social development and ecological and environmental protection in order to create a good production and living environment for the people. This will enable us to carry out the construction of ecological civilization smoothly. Focusing on promoting green development and advocating sustainable design is a simple model, and it controls the social, environmental and economic sectors. The interdependence and mutual complement of the three sectors promote sustainable development, and so does sustainable development of handicrafts.

The sustainable design of handicrafts is an interdisciplinary subject with groundbreaking innovations and high creativities, and it is responsible for the design of human real world. The sustainability is not an accessory in design, but an indispensable part of it.

\section{CONCLUSION}

Under the current trend of the craft culture technology renaissance, in the situation that the revival of traditional technology as well as the protection and inheritance of intangible cultural heritage have become hot topics today, and under the close attention of promoting green 
development and green living, As a kind of brand-new research innovation and design concept, waste material in the creation of handicraft culture, although started late or even in its infancy, the trend is inevitable and it meets the needs of modern market development and is consistent with a sustainable and developing society In the field of future handicraft design, it can accelerate the upgrading of handicraft design, promote social and economic development, improve people's consumption concepts and living environment, promote the balance between man and the ecology, and it has broad development prospects and new development directions. We should extensively use the ecology design idea of applying waste materials in the creation of handicraft culture and make it more and more popular, and make further research and innovation to reflect the connotation of handicraft design of resources saving, low-carbon and environmentally-friendly, ecological health and culture charms. At the same time, we should call for consumers to reflect on the environmental and ecological damage caused by modern science and technology culture, and call for designers to promote innovative design concepts of recycled waste materials. Nowadays, energy-saving and environment-protect are very popular, we call for the green design concept of using waste materials in the creation of craft culture becoming the right choice for people.

\section{REFERENCES}

[1] Baidu Encyclopedia on Waste http://baike.baidu.com/view/1497437.htm.

[2] Quanheng Li. 《Analysis on the Sustainability of Home Supplies Design》 [M]. ICASSEE 2017, ISBN(on-line):978-94-6252-438-5, 2017, 11: 277-279.

[3] [Japanese] Translated by Liu Zongyue, Xu Yiyi. Craft Culture [M]. Guilin: Guangxi Normal University Press, 2011.01. [日]柳宗悦. 徐 艺乙, 译. 工艺文化 [M]. 桂林: 广西师范大学出版社, 2011.01.

[4] Liu Xiaqing, Zhang Qianhui. Research on Design Method of Reusing Waste Materials Based on Sustainable Concept [J]. Packaging Engineering, 2017, 01:86-88. 刘夏清, 张芉慧. 基于可持续理念的 废弃材料再利用设计方法研究 [J]. 包装工程, 2017, 01: 86-88.

[5] Li Quanheng. Innovative Design of "Reuse of Waste materials" in Home Decorations Design [J]. Design, 2014, 07: 190-191. 李全恒. 家居饰用品设计中 “废弃物再利用” 创新设计 $[J]$. 设计, 2014 , 07: 190-191.

[6] Yang Xiaoling, Han Wenya. Green Living Promotes Green Development [J]. Environmental Protection Science, 2015, 05:22-25. 杨小玲, 韩文亚. 绿色生活推动绿色发展 $[\mathrm{J}]$. 环境保护科学, 2015, 05: 22-25. 